\title{
Lithium Iron Phosphate Powders and Coatings Obtained by Means of Inductively-Coupled Thermal Plasma
}

\author{
K. Major ${ }^{1}$, J. Veilleux ${ }^{2}$ and G. Brisard ${ }^{1}$ \\ ${ }^{1}$ Department of Chemistry, Université de Sherbrooke, 2500 Boul. de l'Université, \\ Sherbrooke, Québec, Canada, J1K 2R1 \\ ${ }^{2}$ Department of Chemical Engineering and Biotechnological Engineering, Université de \\ Sherbrooke, 2500 Boul. de l'Université, Sherbrooke, Québec, Canada, J1K 2R1
}

Note: This article is an invited paper selected from presentations at the 2015 International Thermal Spray Conference, held May 11-14, 2015, in Long Beach, California, USA, and has been expanded from the original presentation. 


\begin{abstract}
Lithium-ion batteries have high energy efficiency and good cycling life and are considered as one of the best energy storage device for hybrid and/or electrical vehicle. Still, several problems must be solved prior to a broad adoption by the automotive industry: energy density, safety and costs. To enhance both energy density and safety, the current study aims at depositing binder-free cathode materials using inductively-coupled thermal plasma. In a first step, lithium iron phosphate $\mathrm{LiFePO}_{4}$ powders are synthesized in an inductively-coupled thermal plasma reactor and dispersed in a conventional polyvinylidene fluoride (PVDF) binder. Then, binder-free $\mathrm{LiFePO}_{4}$ coatings are directly deposited onto nickel current collectors by solution precursor plasma spraying (SPPS). The morphology, microstructure and composition of the synthesized $\mathrm{LiFePO}_{4}$ powders and coatings are fully characterized by electronic microscopy, X-ray diffraction and X-ray photoelectron spectroscopy (XPS). Quantifying Li with XPS requires the substitution of iron with manganese in the SPPS precursors $\left(\mathrm{LiMPO}_{4}\right.$, where $\mathrm{M}=\mathrm{Fe}$ or $\left.\mathrm{Mn}\right)$. The plasma-derived cathodes (with and without PVDF binder) are assembled in button cells and tested. Under optimized plasma conditions, cyclic voltammetry shows that the electrochemical reversibility of plasma-derived cathodes is improved over that of conventional sol-gel derived $\mathrm{LiFePO}_{4}$ cathodes.
\end{abstract}

Keywords: SPPS, Lithium-ion battery, $\mathrm{LiFePO}_{4}$, nanopowders, coatings, inductivelycoupled thermal plasma 


\section{Introduction}

The original lithium ion battery (LIB) developed and commercialized in 1991 by Sony, Japan, included a lithium cobalt oxide cathode and a graphite anode [1]. These two electrode materials are still widely used today, although several studies have aimed at replacing the expensive and toxic cobalt-containing cathode [2], at developing stable anodes with high capacities [3] and at improving LIB specific energy, power, safety and reliability [4]. Owing to its abundant material supply and low cost, non-toxicity, relatively high theoretical capacity $\left(170 \mathrm{mAh}^{-1}\right)$, relatively high discharge voltage, high reversibility, long life and excellent thermal safety, lithium iron phosphate $\left(\mathrm{LiFePO}_{4}\right)$ has been perceived as a promising cathode material for lithium ion batteries $[5,6]$. Still, its low electronic and ionic conductivities have prevented its wide-spread application in electric vehicle (EV) applications [7].

Improving the electrical performance of $\mathrm{LiFePO}_{4}$ requires minimizing the particle size, adding carbon to the particles (either as a coating or as an additive to the binder) or substituting some of the Fe atoms by supervalent cations $[1,8]$. Eliminating the binder (e.g. polyvinylidene fluoride - PVDF), which does not contribute to the accumulation of lithium ions, could also improve the energy density of $\mathrm{LiFePO}_{4}$ cathode. These four ways of improving $\mathrm{LiFePO}_{4}$ can be addressed by thermal plasma processes and, in particular, by inductively-coupled thermal plasmas which are known for their ability to produce nanosized particles, core-shell nanostructures (including metal or metal oxides enclosed within a carbon shell) and coatings with a plurality of microstructures [9-11]. In addition, solution precursor plasma spraying (SPPS) offers a thorough control of the chemistry of 
the materials to be deposited [12-15], which is an asset to develop partially substituted $\mathrm{LiFe}_{1-\mathrm{x}} \mathrm{M}_{\mathrm{x}} \mathrm{PO}_{4}$ cathodes, where $\mathrm{M}$ is a supervalent cation such as $\mathrm{Mn}$ or Co.

This great potential of thermal plasma processes to develop nanomaterials and coatings for Li-ion batteries remains to be fully explored. The Additive Manufacturing Process Laboratory of the University of Michigan-Dearborn has pioneered the work in this field by proposing a scalable roll-to-roll thermal spray deposition process for Li-ion battery electrodes [16], including $\mathrm{LiCoO}_{2}$ [17], $\mathrm{V}_{2} \mathrm{O}_{5}$ [18] and $\mathrm{LiFePO}_{4}$ [19] cathodes, as well as $\mathrm{Co}_{3} \mathrm{O}_{4}$ anodes [20]. In this roll-to-roll deposition process opened to the atmosphere (Fig. 1), precursors such as powders, solutions and gases are axially injected into the plasma jet. The precursors are atomized, heated and accelerated towards the rolling substrate to form a film. The substrate is made of a flexible metal foil that will later act as a current collector for the Li-ion battery. If required, the deposited film can be exposed to an additional heat source to modify its crystallographic phase, microstructure or topology [16]. Relatively few details are provided concerning the plasma deposition conditions of $\mathrm{LiFePO}_{4}$ cathodes [19], although problems related to iron oxidation during the deposition process in air at atmospheric pressure are likely to occur. Other approaches under controlled atmospheres include using inductively-coupled thermal plasma processes to develop nanomaterials with enhanced electrochemical properties, such as silicon nanowires [21] or nanostructured lithium titanates powders [22], both of which to be dispersed in conventional binders in existing Li-ion battery anodes manufacturing facilities. 
In this work, an inductively-coupled thermal plasma is used to: i) synthesize submicron $\mathrm{LiFePO}_{4}$ powders; and ii) deposit binder-free $\mathrm{LiFePO}_{4}$ coatings directly onto a current collector. Both processes begin with $\mathrm{LiFePO}_{4}$ precursors in solution. The morphology, chemical and phase compositions of the synthesized $\mathrm{LiFePO}_{4}$ powders and coatings are studied. The powders are dispersed in PVDF to simulate a conventional cathode. Then, both type of plasma-derived cathodes (PVDF-bound powders and binder-free coatings) are assembled in CR2032 button cells to evaluate and to compare their electrochemical performance. CR2032 is the name of a standard battery size $(3.2 \mathrm{~mm}$ thick and $20 \mathrm{~mm}$ in diameter), as given by the International Electrotechnical Commission.

\section{Experimental Procedure}

\subsection{Formulation of the $\mathrm{LiFePO}_{4}$ Precursor Solution}

The precursors selected for the synthesis of $\mathrm{LiFePO}_{4}$ from a sol-gel route are oxalic acid (Aldrich, 98\%), iron phosphate dihydrate (Aldrich Chemistry) and lithium hydroxide (Sigma-Aldrich, 98\%), initially with stoichiometric molar ratios [6]. A 40\% excess of Li is added to compensate for its strong vaporization when the solution is injected into the plasma jet and to retrieve products (powders and coatings) with a stoichiometric Li:Fe ratio. The reactants are dissolved in water and heated to $90^{\circ} \mathrm{C}$ for one hour. The waterbased solution is cooled to $60^{\circ} \mathrm{C}$ prior to its atomization inside the plasma reactor. Interestingly, the oxalic acid can intrinsically provide the carbon source to improve the conductivity of the plasma-derived $\mathrm{LiFePO}_{4}$ since the material is synthesized in a reducing atmosphere. In fact, the global chemical reaction is

$$
2 \mathrm{FePO}_{4}+6 \mathrm{H}_{2} \mathrm{C}_{2} \mathrm{O}_{4}+2 \mathrm{LiOH} \rightarrow 2 \mathrm{LiFePO}_{4}+7 \mathrm{CO}_{2}+5 \mathrm{CO}+7 \mathrm{H}_{2} \mathrm{O}
$$


where the produced $\mathrm{CO}_{2}$ and $\mathrm{CO}$ are likely to be further reduced within the argonhydrogen plasma to provide the carbon source. Still, an additional source of carbon, such as glucose, would be needed to achieve the carbon loading typically reported in conventional cathodes [8].

\subsection{Synthesis of the $\mathrm{LiFePO}_{4}$ Powders}

An inductively-coupled thermal plasma torch (PL50, Tekna Plasma Systems Inc., Sherbrooke, Québec, Canada) operated under vacuum is employed to synthesize $\mathrm{LiFePO}_{4}$ powders (Fig. 2). The plasma torch is connected to a $3 \mathrm{MHz}$ Lepel RF power supply and the power is maintained between $28-32 \mathrm{~kW}$. The central plasma gas is argon and the sheath gas consists in a mixture of argon and hydrogen. Hydrogen provides a reducing atmosphere which helps maintaining the proper oxidation state of iron $\left(\mathrm{Fe}^{2+}\right)$ within the plasma. The carrier gas used to atomize the precursor solution within the plasma is also argon. The reactor pressure is adjusted to 200 torr. The feed rate of the precursors is set to $10 \mathrm{ml} / \mathrm{min}$ using a peristaltic pump. The operational parameters for plasma synthesis are summarized in Table 1.

\subsection{Deposition of the $\mathrm{LiFePO}_{4}$ Coatings}

The plasma conditions prevailing for the deposition of $\mathrm{LiFePO}_{4}$ coatings are similar to those for the powder synthesis (plasma and sheath gases, power, reactor pressure and precursor injection rate). Still, the reactor chamber differs, as illustrated in Fig. 3, and allows for the successive deposition of $\mathrm{LiFePO}_{4}$ layers onto a substrate. The plasma torch is equipped with a supersonic nozzle to increase the velocity of the plasma jet. The torch 
stand-off distance is kept constant at $14 \mathrm{~cm}$ to directly deposit coatings onto $50 \mu \mathrm{m}$-thick nickel substrates, which will act as current collectors for the electrochemical tests. The displacement of the Ni substrate under the plasma jet is done using a water-cooled robotized arm at a rate of $35 \mathrm{~mm} / \mathrm{s}$, for a total of 20 return passes. Deposited $\mathrm{LiFePO}_{4}$ coatings are then annealed under the plasma jet to improve their crystallinity. The operational parameters for plasma deposition are summarized in Table 2.

\subsection{Materials Characterization}

The synthesized $\mathrm{LiFePO}_{4}$ powders and the deposited $\mathrm{LiFePO}_{4}$ coatings are characterized for morphology, chemical and phase compositions. The morphology of the powders is observed with a scanning electron microscope (Hitachi S-4700) and a transmission electron microscope (Hitachi H-7500), while the phase structure is obtained by X-ray diffraction (PANalytical X'pert Pro MRD) equipped with a PIXCel detector using the Bragg-Brentano geometry and $\mathrm{CuK}_{\alpha 1}$ radiation. The chemical composition is assessed by energy dispersive X-ray spectroscopy (OXFORD Instruments Silicon Drift Detector XMax $50 \mathrm{~mm}^{2}$ ) and by X-ray photoelectron spectroscopy (Kratos Analytical Axis Ultra DLD). The identification and quantification of the Li1s peak by XPS is problematic with $\mathrm{LiFePO}_{4}$; indeed, the weak Li1s peak is buried under the stronger Fe3p peak around $55.5 \mathrm{eV}$ [23-25]. Therefore, a $\mathrm{LiMnPO}_{4}$ powder (for which such peak overlap does not occur) is synthesized by replacing the iron phosphate precursor in solution by manganese nitrate and phosphoric acid.

\subsection{Electrochemical Characterization}


Very slow cyclic voltammetry is performed to evaluate the performance of the plasmaderived $\mathrm{LiFePO}_{4}$ cathodes using a potentiostat (Princeton Applied Research 273A). The current intensity is measured as a function of voltage at various scan rates (from 0.05 to $0.2 \mathrm{mV} / \mathrm{s}$ ). The plasma-synthesized $\mathrm{LiFePO}_{4}$ powder is mixed with acetylene black and PVDF in a weight ratio of $85: 7.5: 7.5$ to form a thin film cathode on a Ni microdisk, whereas the plasma-deposited $\mathrm{LiFePO}_{4}$ coatings are used directly as sprayed onto the $\mathrm{Ni}$ current collector as a cathode in a 2032 button cell. In both setups, the electrolyte is $1 \mathrm{M}$ $\mathrm{LiPF}_{6}$ dissolved in a mixture of ethyl methyl carbonate (Sigma-Aldrich) and dimethyl carbonate (Sigma-Aldrich) with a volume ratio of 3:7. The button cell has a 2-electrode geometry, where the counter electrode is disk-shaped lithium metal. In the 3-electrode electrochemical cell used to test the PVDF-bound cathode, the counter electrode and the reference electrodes are pure lithium rods.

\section{Results and Discussion}

\subsection{Materials Characterization}

The characteristic morphology of the plasma-synthesized $\mathrm{LiFePO}_{4}$ powder collected in the filters is shown in Fig. 4. The particles have a spherical morphology as observed by SEM (Fig. 4) and the size distribution is relatively narrow (approximately $50-100 \mathrm{~nm}$ in diameter). It is expected that the dispersion of this powder in PVDF will be facilitated by the spherical morphology, while the small size distribution should help improving the electrical performance of the $\mathrm{LiFePO}_{4}$ cathode, that is, the lithiation-delithiation process. 
The TEM image (Fig. 5a) also shows particles with a spherical morphology, while some are facetted. In addition, little amounts carbon can be observed as amorphous sheets rather than as shells surrounding the nanoparticles (Fig. 5b). The latter observation confirms our hypothesis that the oxalic acid alone can act as a source of carbon under a controlled atmosphere synthesis.

The plasma-deposited $\mathrm{LiFePO}_{4}$ coatings show an interesting multi-scale porosity (Fig. 6) ranging from tens of microns (Fig. 6b) to submicron sizes (Fig. 6c) that should contribute to enhance the lithiation-delithiation process. The large $50 \mu \mathrm{m}$ islands shown in Fig. 6a are indeed formed by the agglomeration of several submicronic melted $\mathrm{LiFePO}_{4}$ particles (Fig. 6c). It is hypothesized that these submicronic particles are formed and melted in flight during the SPPS process, and that they then agglomerate and partly solidify together prior to impinging the current collector owing the long $140 \mathrm{~mm}$ spray distance. The deposited coatings, approximately $60 \mu \mathrm{m}$ thick, also show a gradient in porosity that increases from the substrate to the surface (Fig. 6d) and which should promote the permeation of the electrolyte.

The XRD patterns of the plasma-synthesized $\mathrm{LiFePO}_{4}$ powders and plasma-deposited $\mathrm{LiFePO}_{4}$ coatings are shown in Fig. 7. The peaks of both patterns are all in good agreement with the standard $\mathrm{LiFePO}_{4}$ olivine structure (JCPDS 00-040-1499). Still, the powder peaks are sharper for equal XRD acquisition time, which suggests an increased degree of crystallinity that can be attributed to a higher processing temperature achieved in the powder reactor. This is in accordance with the initial nozzle choice (subsonic for 
powders versus supersonic for coatings), which allows for a longer residence time of the precursors within the plasma jet. Moreover, the reactor geometry used for powder synthesis also accounts for higher temperatures, the expansion volume being greatly reduced when compared to that of the coating reactor. Finally, when depositing $\mathrm{LiFePO}_{4}$ coatings onto $50 \mu \mathrm{m}$-thick $\mathrm{Ni}$ substrates/current collectors, great care (i.e. low temperature conditions) must be taken in preserving the integrity of the Ni to maintain its current collection efficiency when assembled in button cells.

As mentioned earlier, an interesting feature of the plasma synthesis/deposition from precursor solution is the ability of incorporating an additional carbon source or of substituting the iron by supervalent cations. In our choice of precursors, the oxalic acid (chemical formula: $\mathrm{HOOC}-\mathrm{COOH}$ ), with its two carbon atoms, may provide an intrinsic carbon source to enhance the electrical performance of the synthesized powders and of the deposited coatings. The reducing atmosphere prevailing in both reactors provides suitable conditions to retrieve carbon in the final products. The presence of carbon, observed by TEM in Fig. 5b, is further analyzed by XPS as shown in Fig. 8a and Fig. 8b. XPS confirms the presence of $\mathrm{C}-\mathrm{C}, \mathrm{C}-\mathrm{H}, \mathrm{C}-\mathrm{O}, \mathrm{C}=\mathrm{O}$ and $\mathrm{COO}$ bonds. Regarding the quantification of $\mathrm{Li}$ (Fig. 8c), it required $\mathrm{LiMnPO}_{4}$ powder samples which were synthesized in a manner similar to that of $\mathrm{LiFePO}_{4}$ powders, but with manganese and phosphate precursors rather than an iron phosphate precursor, as explained previously. The analysis of the XPS spectrum generally confirms the expected atomic ratios for $\mathrm{Li}$, $\mathrm{Mn}, \mathrm{P}$ and $\mathrm{O}$ (Table 3). Further quantitative analysis on the bulk would be required to confirm the noted deficiency in P (e.g. by X-ray fluorescence). 


\subsection{Electrochemical Characterization}

The cyclic voltammetry (CV) curves of the cathode made of plasma-synthesized $\mathrm{LiFePO}_{4}$ powders dispersed in PVDF and that of the binder-free plasma-deposited $\mathrm{LiFePO}_{4}$ cathode are shown in Fig. 9a and Fig. 9b, respectively. The CV curves show a positive anodic peak (charging phase) around $3.5 \mathrm{~V}$ and a negative cathodic peak (discharging phase) between 3.2 and $3.4 \mathrm{~V}$. The peak current increases with the scan rate: the anodic/cathodic peaks shift to higher/lower potentials, which is characteristic of an increased kinetic polarization and of an increased internal resistance at higher scan rates. The potential difference $\Delta \mathrm{E}$ between the anodic and the cathodic peaks, as reported in Table 4, is an indicator of the electrochemical reversibility of the cell. One can observe that the plasma-synthesized $\mathrm{LiFePO}_{4}$ powder outperforms the plasma-deposited coatings in terms of electrochemical cell reversibility. Tests performed using a commercially available $\mathrm{LiFePO}_{4}$ powder (MTI Corporation, Richmond, CA, USA) mixed with acetylene black and PVDF in a weight ratio of 85:7.5:7.5 to form a thin film cathode on a $\mathrm{Ni}$ microdisk gave $\Delta \mathrm{E}$ results of $0.28 \mathrm{~V}$ and $0.36 \mathrm{~V}$ at scan rates of $0.05 \mathrm{mV} / \mathrm{s}$ and 0.20 $\mathrm{mV} / \mathrm{s}$, respectively. Thus, the plasma-synthesized $\mathrm{LiFePO}_{4}$ powders show a significantly improved reversibility, while the plasma-deposited $\mathrm{LiFePO}_{4}$ coatings perform similarly to the commercial powder.

In addition, the sharper anodic and cathodic peaks of the powder-derived cathode suggest faster lithium-ion diffusion, but the different test geometries do not allow for a direct comparison of the measured currents. On the contrary, preliminary calculations of the Li- 
ion diffusion coefficient using the Randles-Sevcik relation rather indicate that the diffusion coefficient is an order of magnitude greater for the plasma-deposited $\mathrm{LiFePO}_{4}$

coating $\left(5 \times 10^{-11} \mathrm{~cm}^{2} / \mathrm{s}\right)$ as opposed to that of the plasma-synthesized powders $\left(5 \times 10^{-12}\right.$ $\mathrm{cm}^{2} / \mathrm{s}$ ). In cyclic voltammetry, the Randles-Sevcik relates the peak current $i_{p}$ to the square root of the product of the scan rate $v$ and the electroactive specie diffusion coefficient $D$, that is $i_{p} \propto[v D]^{1 / 2}$. Reported values in the literature for the Li-ion diffusion coefficient range from $10^{-16}$ to $10^{-9} \mathrm{~cm}^{2} / \mathrm{s}[2,26,27]$, as measured with galvanostatic and potentiostatic intermittent titration techniques. It should be noted that the application of the Randles-Sevcik relation to the diffusion of Li-ion in solid materials is a first approximation that must be validated, but the results make sense when observing that the plasma-deposited $\mathrm{LiFePO}_{4}$ coatings are binder-free, porous cathodes offering less resistance to the diffusion of Li-ions as opposed to the denser cathode made of PVDFbound $\mathrm{LiFePO}_{4}$ powders.

Further tests are needed to confirm the last two observations (reversibility and Li-ion diffusion coefficient). In fact, having identical electrochemical cell geometry (e.g. 2032 button cell) for both the plasma-synthesized $\mathrm{LiFePO}_{4}$ powders and plasma-deposited $\mathrm{LiFePO}_{4}$ coatings would allow a direct comparison of the CV curves and, consequently, the conclusions to be drawn on a common basis.

\section{Conclusions}

To conclude, inductively-coupled thermal plasma processes were successively applied to the synthesis of $\mathrm{LiFePO}_{4}$ powders and to the deposition of binder free $\mathrm{LiFePO}_{4}$ coatings 
from precursors in solution. The powders were dispersed in PVDF binder to form a conventional cathode, while the coatings were used directly as deposited for the electrochemical tests. It was shown that the plasma conditions are suitable to obtain the $\mathrm{LiFePO}_{4}$ olivine structure, with higher crystallinity for the powder reactor owing to higher temperatures. The cyclic voltammetry tests revealed a good reversibility of the electrochemical cells for the plasma-obtained $\mathrm{LiFePO}_{4}$ powders and coatings, with promising Li-ion diffusion coefficients. To explain these results, the role of carbon, which has been detected in the produced samples, shall be investigated. Further tests are also needed to compare the performance of the plasma-synthesized $\mathrm{LiFePO}_{4}$ powders to conventional sol-gel derived $\mathrm{LiFePO}_{4}$ powders, and that of plasma-deposited binder-free $\mathrm{LiFePO}_{4}$ coatings to the usual cathodes. In particular, the capacity and the cyclability of the materials shall be evaluated.

\section{Acknowledgements}

The financial support by the Natural Sciences and Engineering Research Council of Canada (NSERC RGPIN-2014-05928) and the Université de Sherbrooke is gratefully acknowledged. The authors also appreciate the helpful technical support from Kossi Béré, Charles Bertrand and Sonia Blais, as well as fruitful discussions with Professor François Gitzhofer. 


\section{References}

[1] Abu-Lebdeh, Y., et al., eds. Nanotechnology for Lithium-ion Batteries. Nanostructure Science and Technology, ed. D.J. Lockwood. 2013, Springer: New York. 282 p.

[2] Ellis, B.L., et al., "Positive Electrode Materials for Li-Ion and Li-Batteries," Chemistry of Materials, Vol. 22, No. 3 (2010), pp. 691-714.

[3] Reddy, M.V., et al., "Metal Oxides and Oxysalts as Anode Materials for Li Ion Batteries," Chemical Reviews, Vol. 113, No. 7 (2013), pp. 5364-5457.

[4] Scrosati, B., et al., "Lithium batteries: Status, prospects and future," Journal of Power Sources, Vol. 195, No. 9 (2010), pp. 2419-2430.

[5] Armand, M., et al., "Building better batteries," Nature, Vol. 451, No. 7179 (2008), pp. 652-657.

[6] Peng, W., et al., "A novel sol-gel method based on FePO4-2H2O to synthesize submicrometer structured LiFePO4/C cathode material," Journal of Power Sources, Vol. 196, No. 5 (2011), pp. 2841-2847.

[7] Zhang, W.-J., "Structure and performance of LiFePO4 cathode materials: A review," Journal of Power Sources, Vol. 196, No. 6 (2011), pp. 2962-2970.

[8] Jugović, D., et al., "A review of recent developments in the synthesis procedures of lithium iron phosphate powders," Journal of Power Sources, Vol. 190, No. 2 (2009), pp. 538-544.

[9] Guo, J., et al., "Development of Nanopowder Synthesis Using Induction Plasma," Plasma Science and Technology, Vol. 12, No. 2 (2010), pp. 188-199.

[10] Fauchais, P.L., et al., Thermal Spray Fundamentals: From Powder to Part, Springer (New York, 2014), 1566 p.

[11] Suetsuna, T., et al., "Synthesis of self-forming core/shell nanoparticles of magnetic metal/nonmagnetic oxide," Acta Materialia, Vol. 78, No. 0 (2014), pp. 320-327.

[12] Fauchais, P., et al., "Parameters Controlling Liquid Plasma Spraying: Solutions, Sols, or Suspensions," Journal of Thermal Spray Technology, Vol. 17, No. 1 (2008), pp. 31-59.

[13] Killinger, A., et al., "Review of New Developments in Suspension and Solution Precursor Thermal Spray Processes," Journal of Thermal Spray Technology, Vol. 20, No. 4 (2011), pp. 677-695.

[14] Muoto, C., et al., "Identification of Desirable Precursor Properties for Solution Precursor Plasma Spray," Journal of Thermal Spray Technology, Vol. 20, No. 4 (2011), pp. 802-816.

[15] Darthout, É., et al., "Lu2O3-SiO2-ZrO2 Coatings for Environmental Barrier Application by Solution Precursor Plasma Spraying and Influence of Precursor Chemistry," Journal of Thermal Spray Technology, Vol. 23, No. 3 (2014), pp. 325-332.

[16] Mohanty, P.S., "In-situ Plasma Synthesis and Deposition Platform for Energy Storage Devices," Advanced Materials \& Processes, Vol. 169, No. 11 (2011), pp. 63-64. 
[17] Pentyala, N., et al., "Binder free porous ultrafine/nano structured $\mathrm{LiCoO} 2$ cathode from plasma deposited cobalt," Electrochimica Acta, Vol. 56, No. 27 (2011), pp. 9851-9859.

[18] Varadaraajan, V., et al., "Direct synthesis of nanostructured V2O5 films using solution plasma spray approach for lithium battery applications," Journal of Power Sources, Vol. 196, No. 24 (2011), pp. 10704-10711.

[19] Mohanty, P.S., et al., Direct thermal spray synthesis of li ion battery components. 2010.

[20] Tummala, R., et al., "Binder free, porous and nanostructured $\mathrm{Co} 3 \mathrm{O} 4$ anode for Liion batteries from solution precursor plasma deposition," Journal of Power Sources, Vol. 199, No. 0 (2012), pp. 270-277.

[21] Lamontagne, P., et al., "Synthesis of silicon nanowires from carbothermic reduction of silica fume in RF thermal plasma," Physica Status Solidi A, Vol. 211, No. 7 (2014), pp. 1610-1616.

[22] Quesnel, F., et al., "Synthesis of lithium titanates nanoparticles in an inductive plasma reactor," OREBA 1.0. Montreal (QC), Canada, 2014. pp.

[23] Rho, Y.-H., et al., "Surface Chemistry of LiFePO4 Studied by Mössbauer and XRay Photoelectron Spectroscopy and Its Effect on Electrochemical Properties," Journal of The Electrochemical Society, Vol. 154, No. 4 (2007), pp. A283-A289.

[24] Saravanan, K., et al., "Storage performance of LiFePO4 nanoplates," Journal of Materials Chemistry, Vol. 19, No. 5 (2009), pp. 605-610.

[25] Castro, L., et al., "Aging Mechanisms of LiFePO4 // Graphite Cells Studied by XPS: Redox Reaction and Electrode/Electrolyte Interfaces," Journal of The Electrochemical Society, Vol. 159, No. 4 (2012), pp. A357-A363.

[26] Prosini, P.P., et al., "Determination of the chemical diffusion coefficient of lithium in LiFePO4," Solid State Ionics, Vol. 148, No. 1-2 (2002), pp. 45-51.

[27] Churikov, A.V., et al., "Determination of lithium diffusion coefficient in LiFePO4 electrode by galvanostatic and potentiostatic intermittent titration techniques," Electrochimica Acta, Vol. 55, No. 8 (2010), pp. 2939-2950. 


\section{Figures}

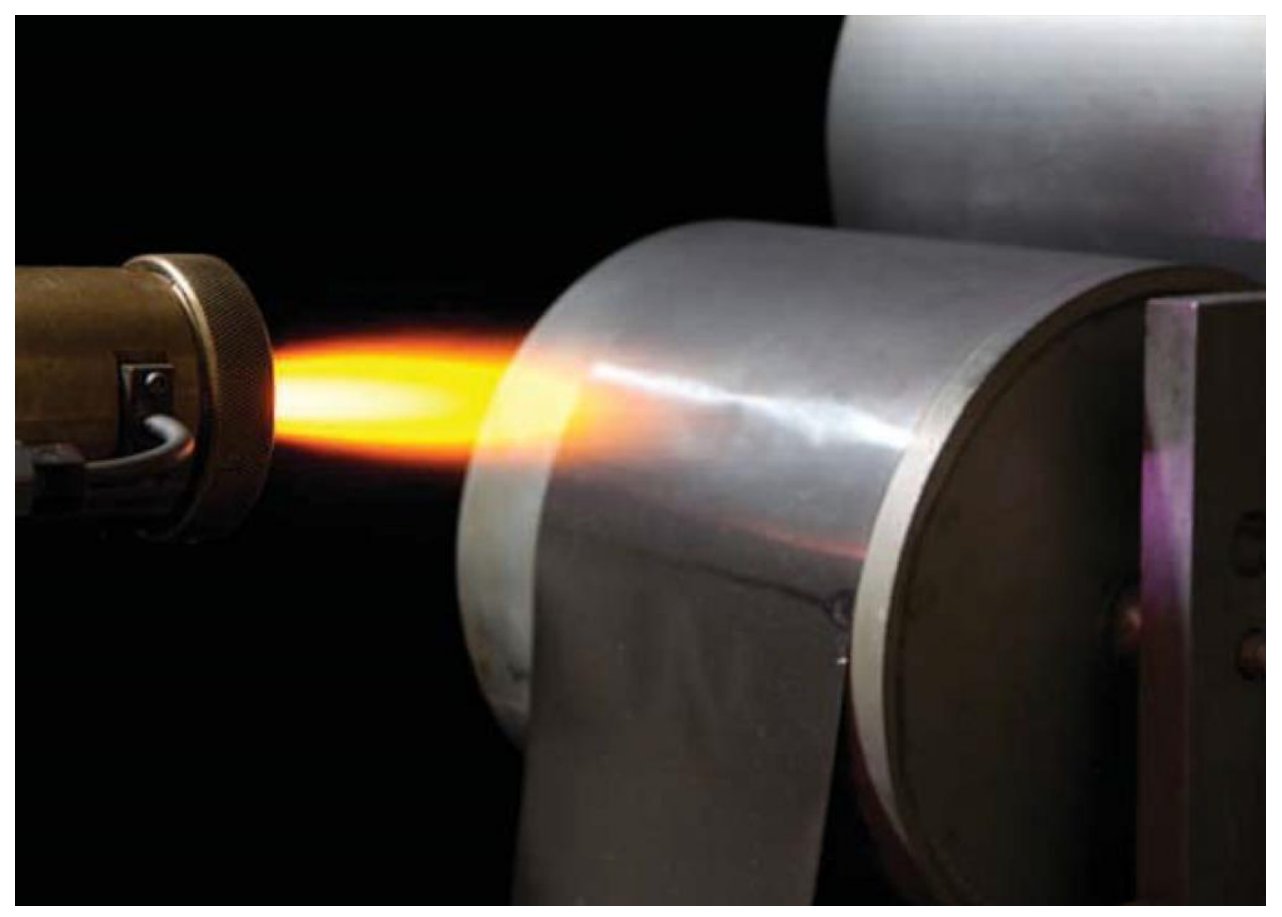

Figure 1: Roll-to-roll deposition process [16]. Reprinted with permission of ASM International. All rights reserved. www.asminternational.org 


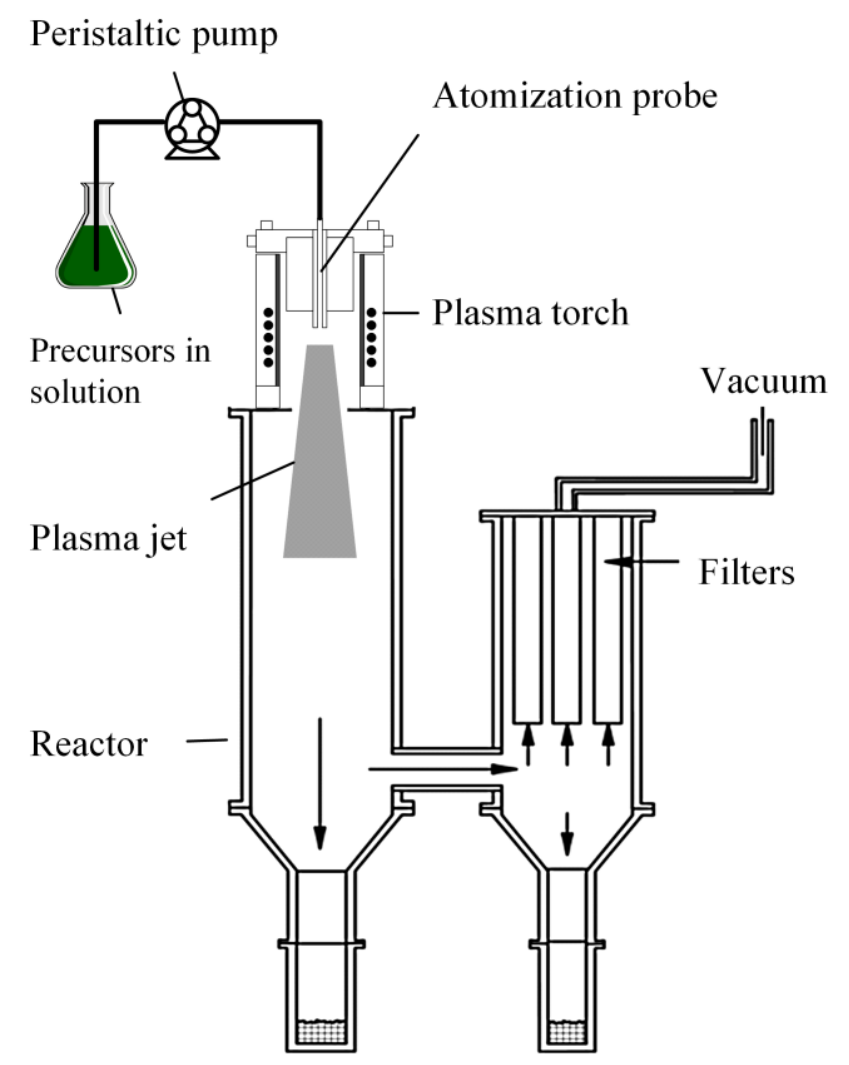

Figure 2: Inductively-coupled thermal plasma reactor used for the synthesis of $\mathrm{LiFePO}_{4}$ powders from precursors in solution. The powder is synthesized in-flight inside the reactor and collected on the reactor walls and on the filters. 


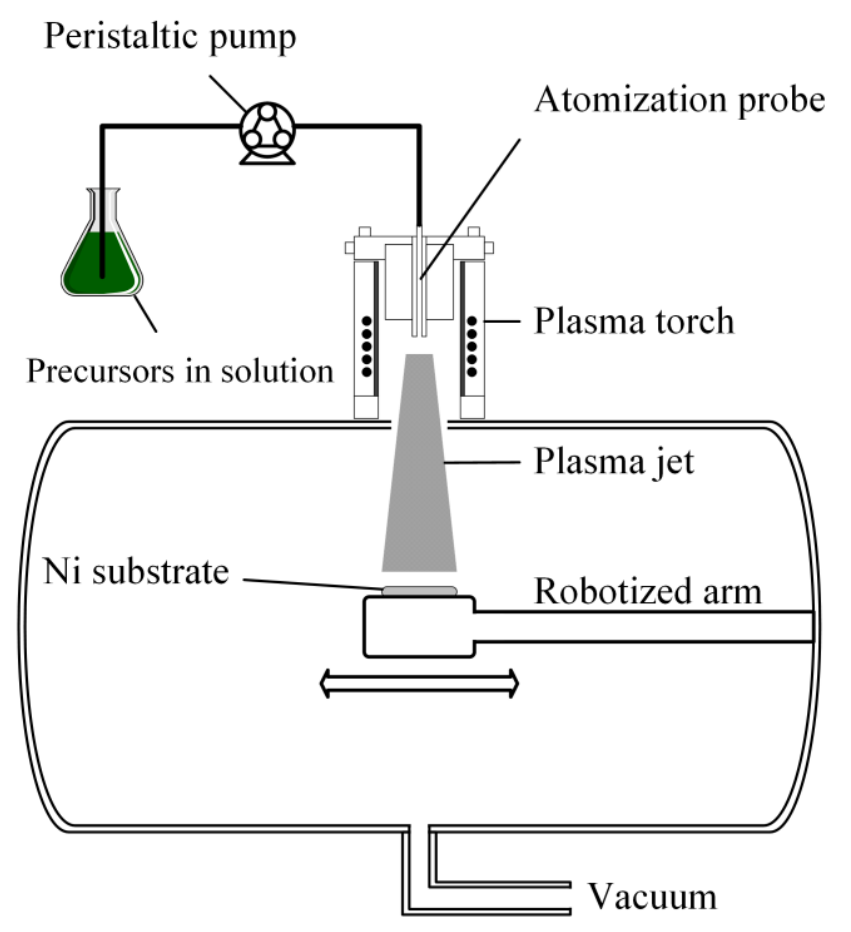

Figure 3: Inductively-coupled thermal plasma reactor used for the deposition of $\mathrm{LiFePO}_{4}$ coatings from precursors in solution. The $\mathrm{Ni}$ substrate is held onto the water-cooled robotized arm using a thermally conductive paste. 


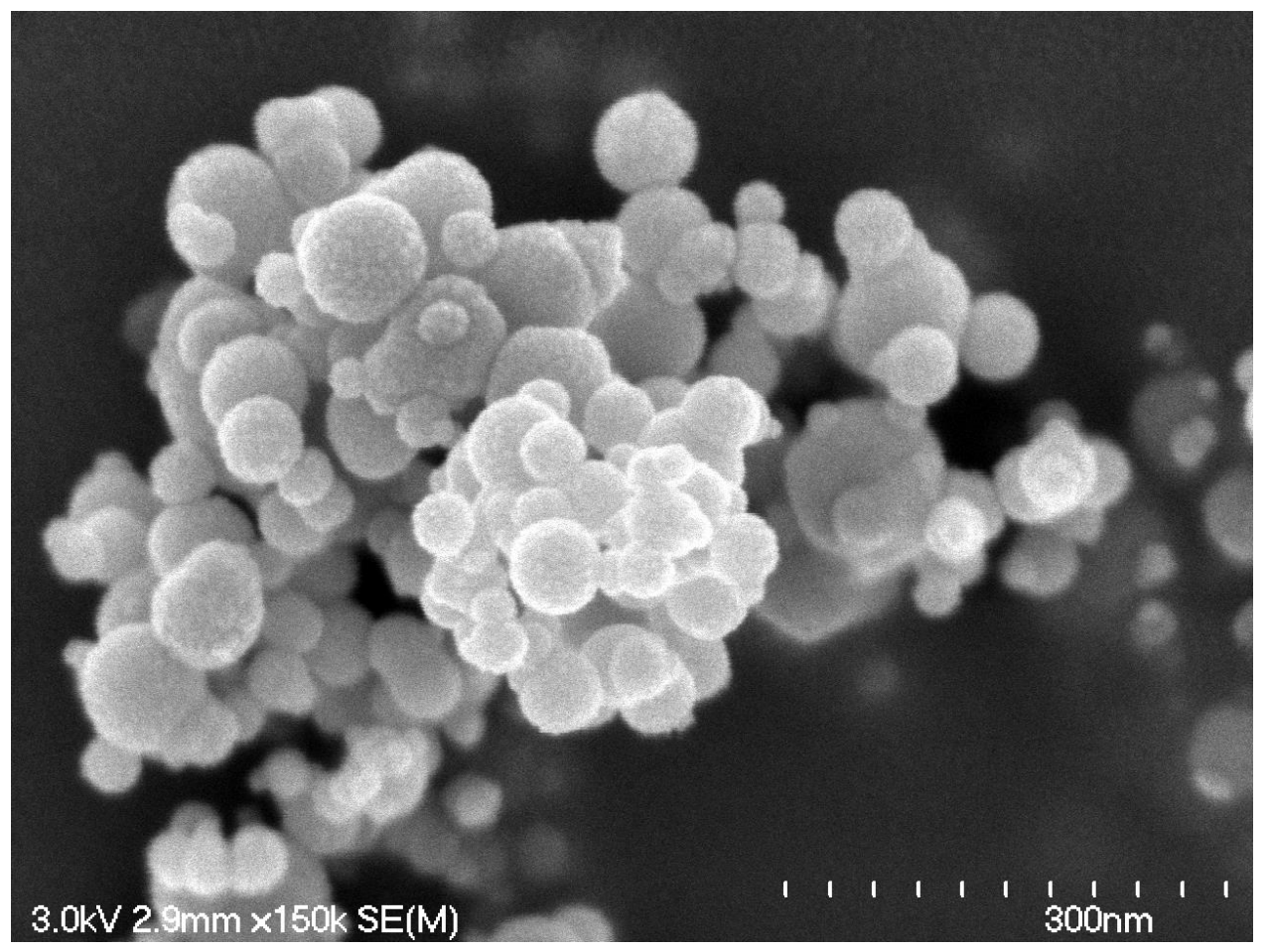

Figure 4: SEM micrograph showing the size distribution and the spheroidal shape of the $\mathrm{LiFePO}_{4}$ powder synthesized. 

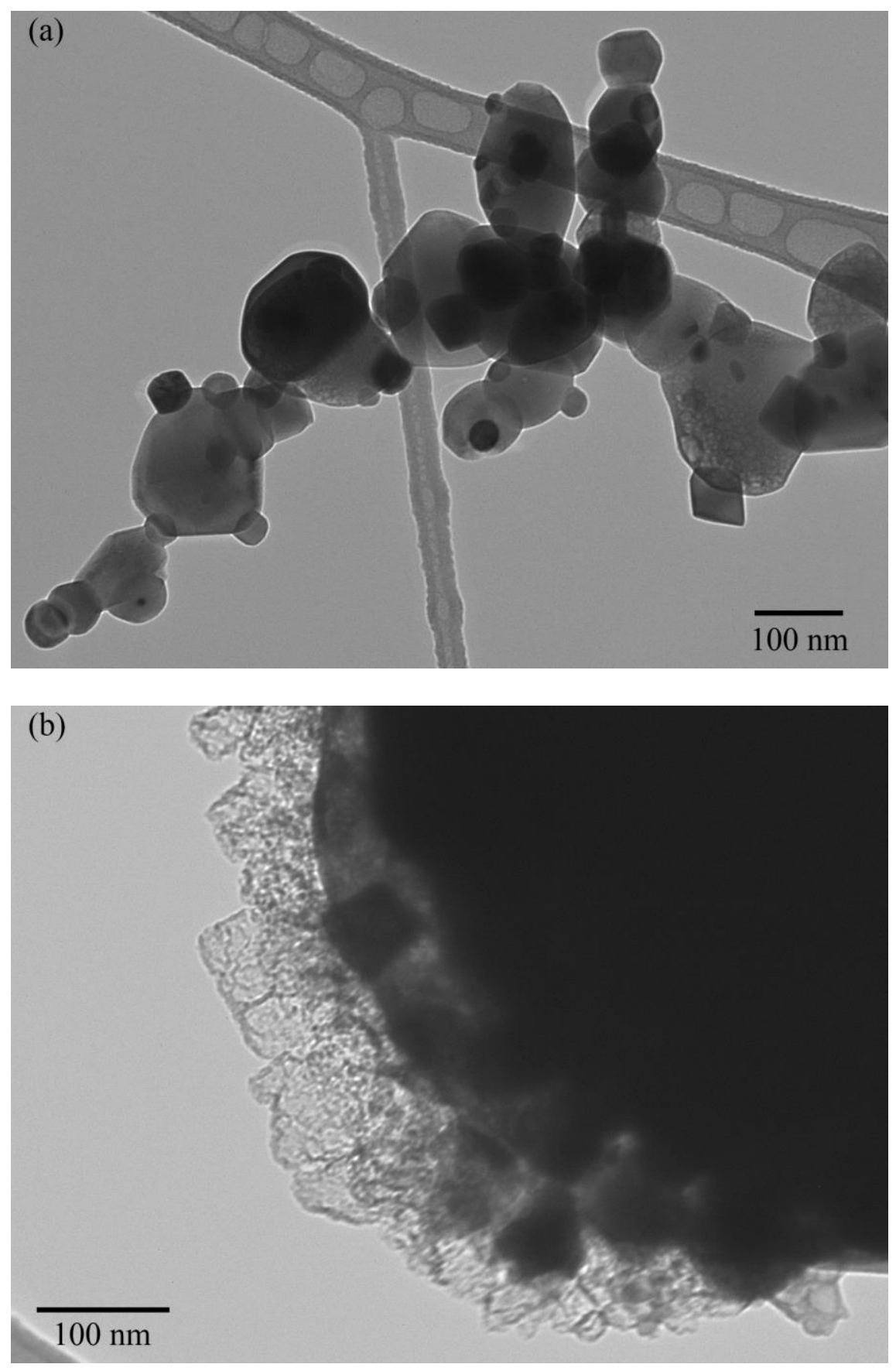

Figure 5: TEM micrographs showing (a) that some particles are facetted and (b) that a small amount of amorphous carbon is present. 

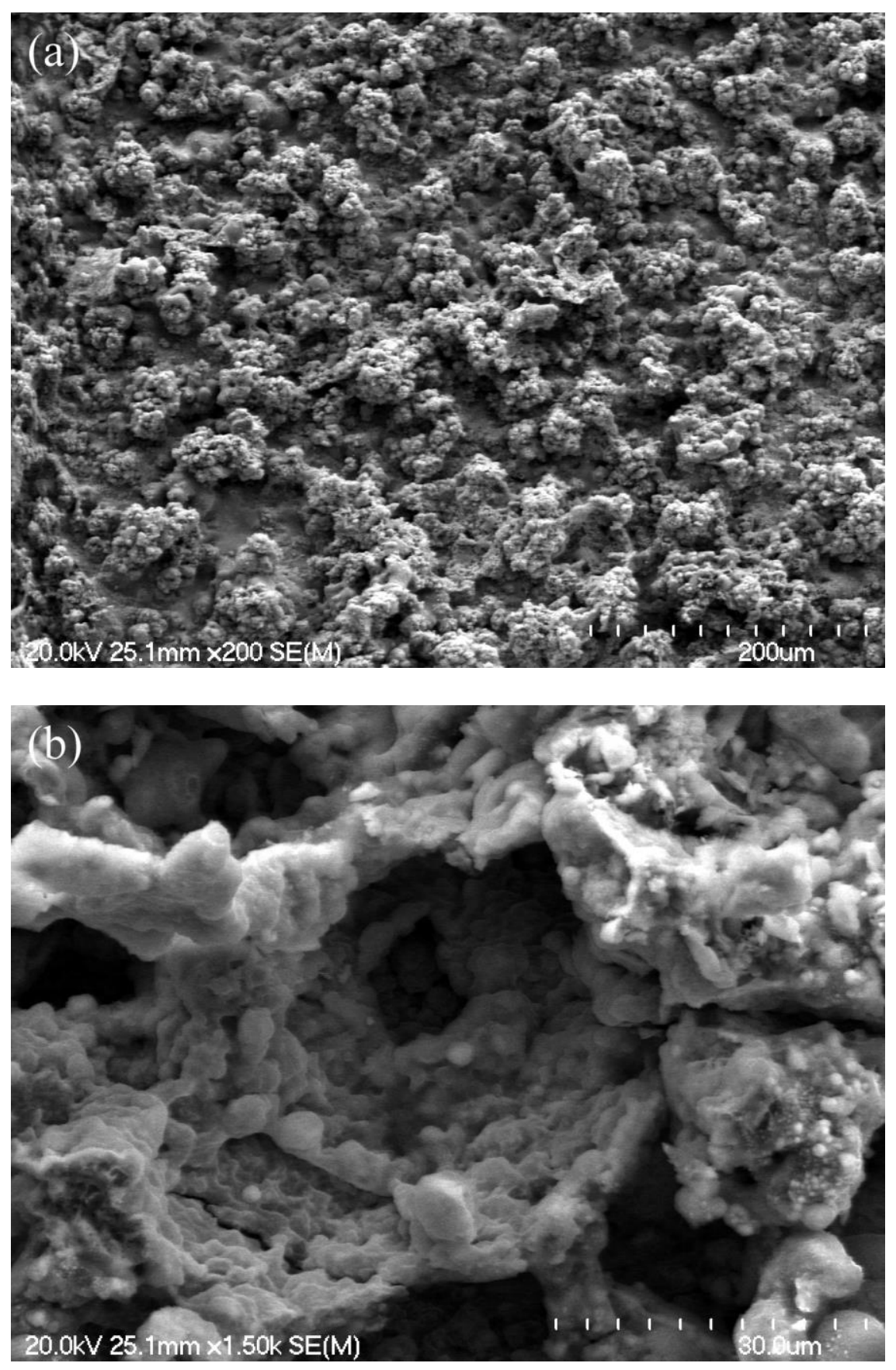

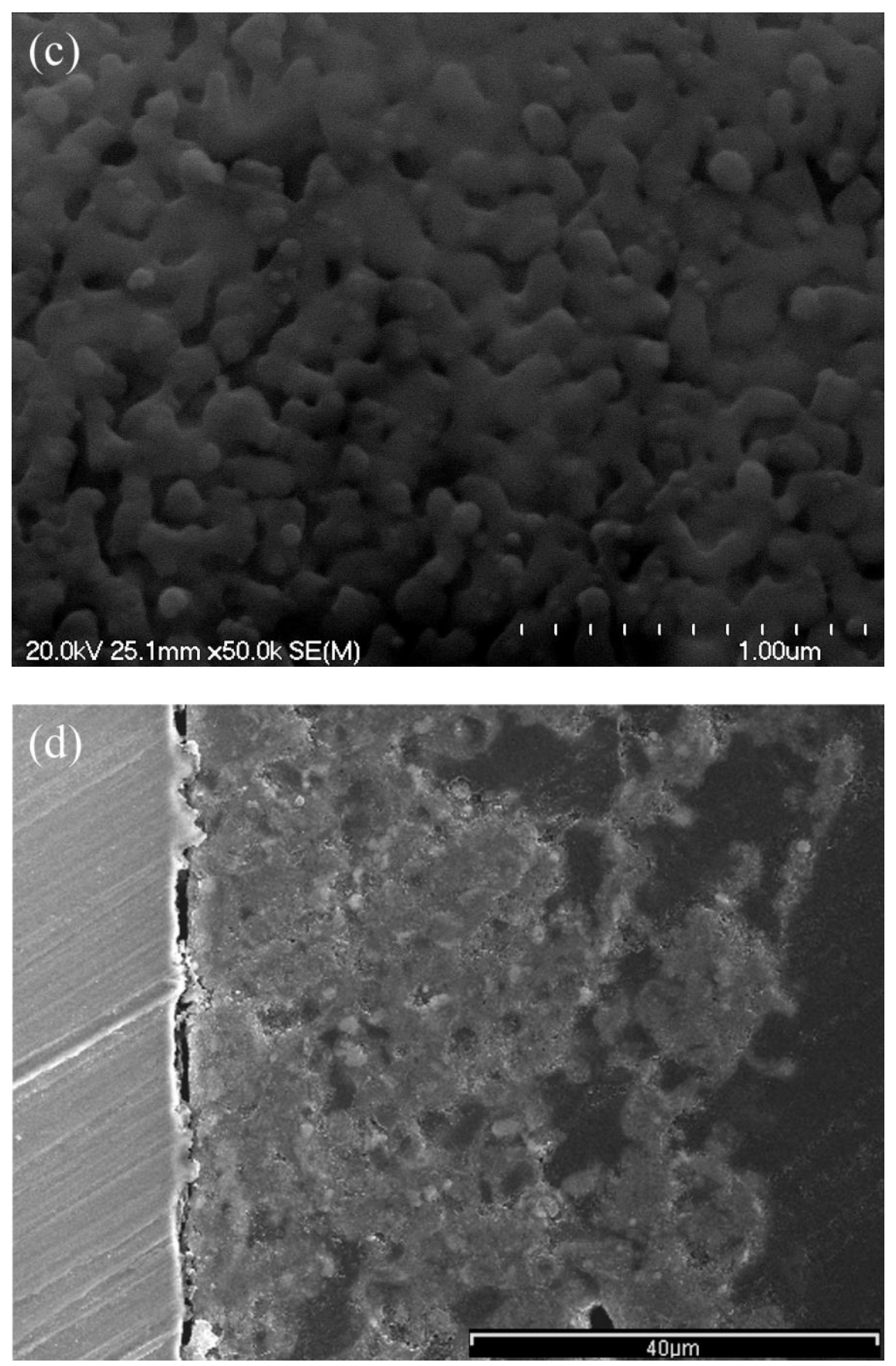

Figure 6: Morphology of the deposited coating as observed by SEM. Top view with a magnification (a) $\times 200$, (b) $\times 1.50 \mathrm{k}$ and (c) $\times 50.0 \mathrm{k}$. (d) Cross-section. 


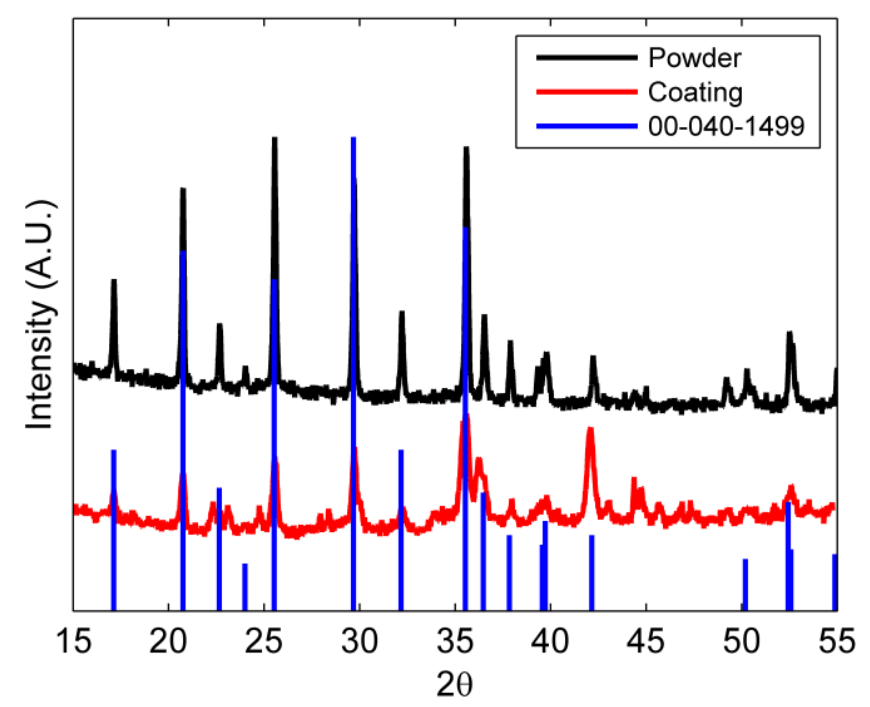

Figure 7: X-ray diffractograms of the $\mathrm{LiFePO}_{4}$ powder and coating obtained by plasma form precursors in solution. 

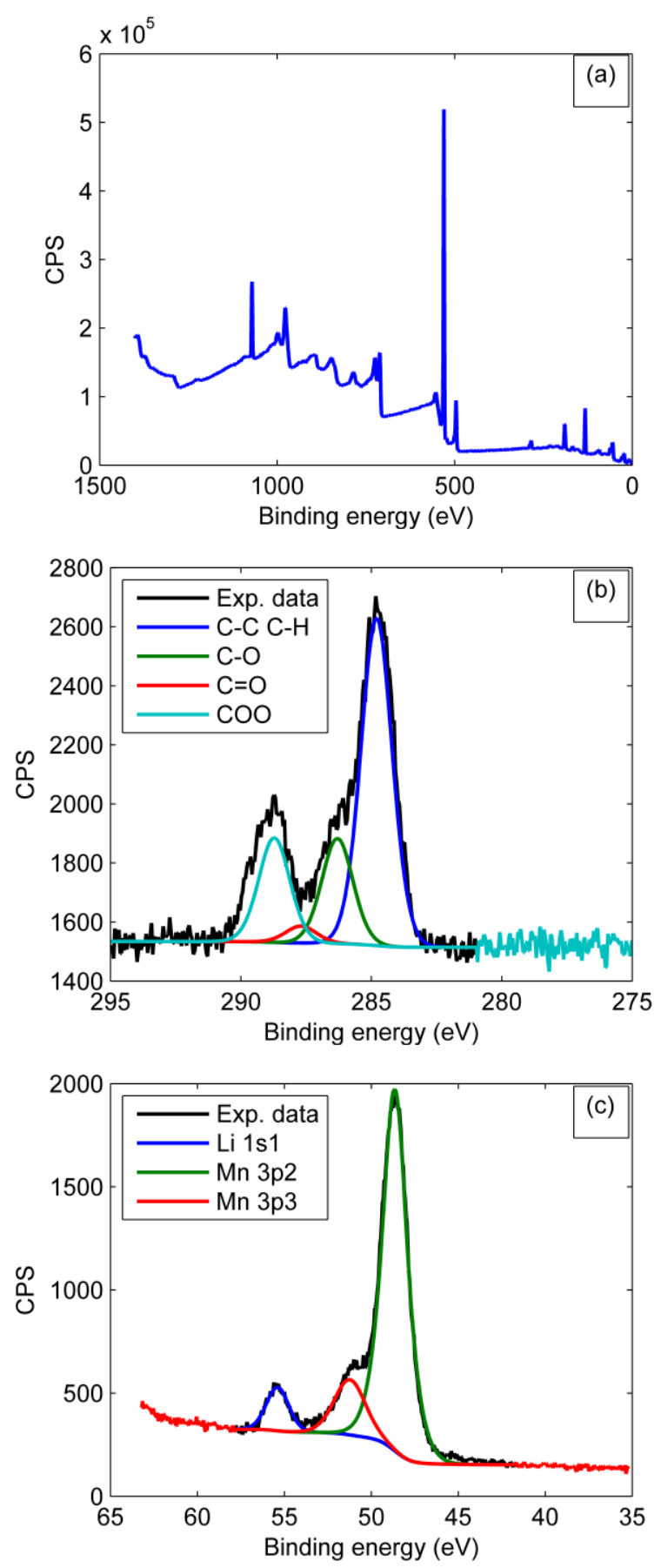

Figure 8: (a) General XPS scan for the plasma-synthesized $\mathrm{LiFePO}_{4}$ powders. (b) Highresolution scan for the plasma-synthesized $\mathrm{LiFePO}_{4}$ powders revealing the presence of $\mathrm{C}$ C, C-H, C-O, C=0 and COO bounds. (c) High-resolution scan for the plasma-synthesized $\mathrm{LiMnPO}_{4}$ powders revealing the Li1s peak besides the Mn3p peak. 

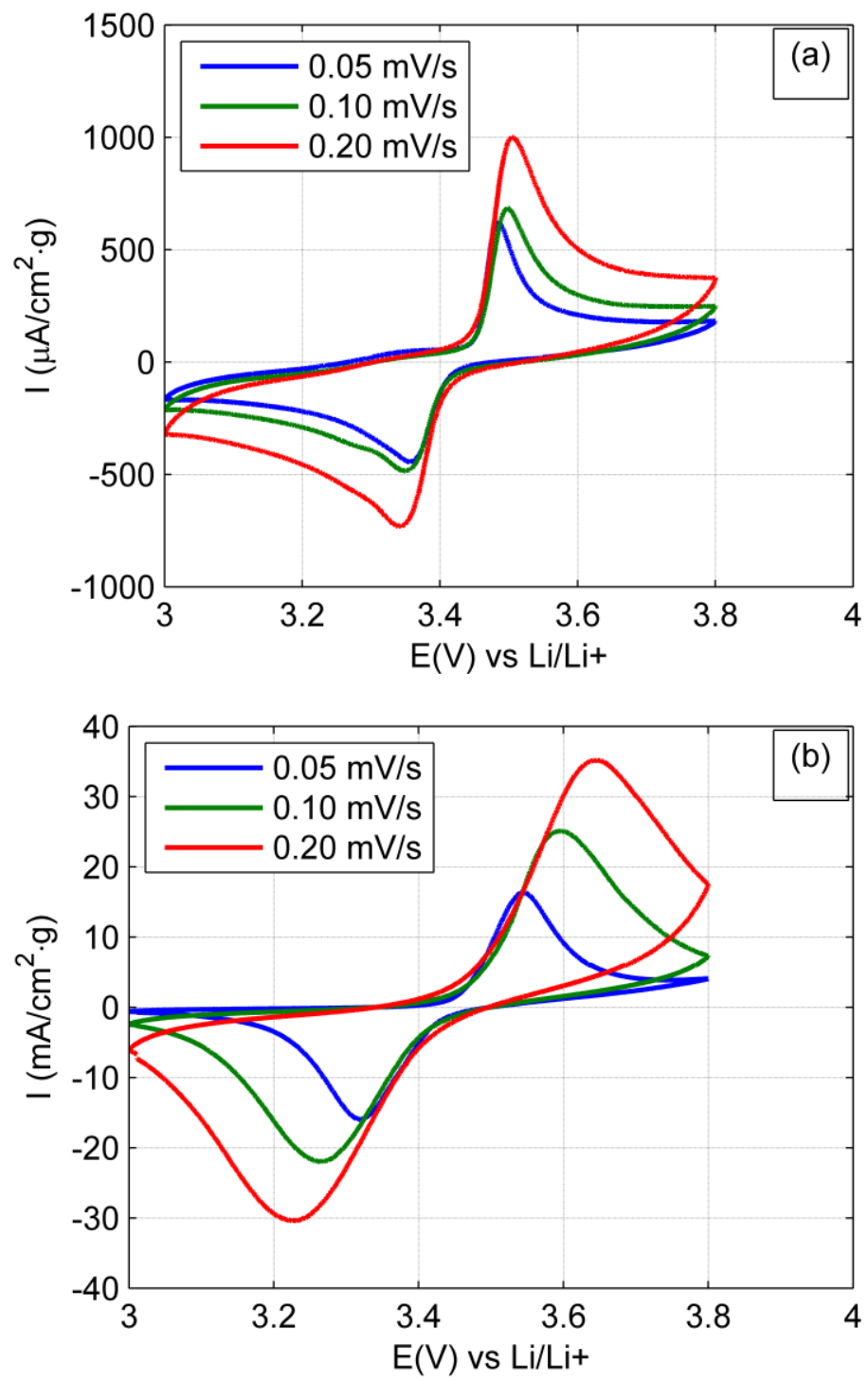

Figure 9: Cyclic voltammetry of (a) $\mathrm{LiFePO}_{4}$ cathode made of plasma-synthesized powders dispersed in PVDF and (b) binder-free, plasma-deposited $\mathrm{LiFePO}_{4}$ cathode. 


\section{Tables}

Table 1: Operational parameters for the synthesis of $\mathrm{LiFePO}_{4}$ powders.

\begin{tabular}{ll}
\hline Parameter & Value \\
\hline Plasma torch & Tekna PL50 \\
Nozzle & Subsonic \\
Central gas flow rate, & $25 \mathrm{~L} / \mathrm{min}$ \\
Argon & \\
Sheath gas flow rate & $72 \mathrm{~L} / \mathrm{min}$ \\
$\quad$ Argon & $5 \mathrm{~L} / \mathrm{min}$ \\
$\quad$ Hydrogen & $10 \mathrm{~L} / \mathrm{min}$ \\
Carrier gas flow rate, & \\
Argon & $10 \mathrm{ml} / \mathrm{min}$ \\
Precursor feed rate & $200 \mathrm{torr}$ \\
Reactor pressure & $30 \mathrm{~kW}$ \\
Power &
\end{tabular}

Table 2: Operational parameters for the deposition of $\mathrm{LiFePO}_{4}$ coatings.

\begin{tabular}{ll}
\hline Parameter & Value \\
\hline Plasma torch & Tekna PL50 \\
Nozzle & Supersonic \\
Central gas flow rate, & $25 \mathrm{~L} / \mathrm{min}$ \\
Argon & \\
Sheath gas flow rate & $72 \mathrm{~L} / \mathrm{min}$ \\
$\quad$ Argon & $5 \mathrm{~L} / \mathrm{min}$ \\
$\quad$ Hydrogen & $10 \mathrm{~L} / \mathrm{min}$ \\
Carrier gas flow rate, & \\
Argon & $10 \mathrm{ml} / \mathrm{min}$ \\
Precursor feed rate & $200 \mathrm{torr}$ \\
Reactor pressure & $30 \mathrm{~kW}$ \\
Power & \\
Spraying parameters & $14 \mathrm{~cm}$ \\
$\quad$ Distance & $35 \mathrm{~mm} / \mathrm{s}$ \\
\hline
\end{tabular}


Table 3: Quantitative XPS analysis of the $\mathrm{LiMnPO}_{4}$ plasma-synthesized powder. $\mathrm{Mn}$ is chosen over Fe to quantify Li without peak convolution.

\begin{tabular}{lc}
\hline Atom/bond & $\begin{array}{l}\text { Atomic percentage } \\
(\mathbf{\%})\end{array}$ \\
\hline $\mathrm{Li}(1 \mathrm{~s})$ & 12.5 \\
$\mathrm{Mn}(2 \mathrm{p})$ & 12.5 \\
$\mathrm{P}(2 \mathrm{p} \mathrm{3/2})$ & 6.6 \\
$\mathrm{O}(1 \mathrm{~s})$ & 51.9 \\
$\mathrm{C}-\mathrm{C}$ or C-H (1s) & 10.1 \\
$\mathrm{C}-\mathrm{O}(1 \mathrm{~s})$ & 1.1 \\
$\mathrm{C}=\mathrm{O}(1 \mathrm{~s})$ & 0.2 \\
$\mathrm{COO}(1 \mathrm{~s})$ & 2.0 \\
Impurities (e.g. Na and S) & 3.1 \\
\hline
\end{tabular}

Table 4: Anodic peak ( $\left.E_{o x}\right)$ and cathodic peak (Ered) locations and corresponding potential differences $(\Delta \mathrm{E})$ as a function of scan rate for the plasma-derived cathodes.

\begin{tabular}{|c|c|c|c|c|}
\hline & $\begin{array}{c}\text { Scan } \\
\text { rate } \\
(\mathrm{mV} / \mathrm{s})\end{array}$ & $E_{o x}(V)$ & $\mathbf{E}_{\text {red }}(\mathbf{V})$ & $\Delta E(V)$ \\
\hline \multirow{3}{*}{ 离 } & 0.05 & 3.48 & 3.36 & 0.12 \\
\hline & 0.10 & 3.50 & 3.34 & 0.16 \\
\hline & 0.20 & 3.50 & 3.35 & 0.15 \\
\hline \multirow{3}{*}{ نُ } & 0.05 & 3.55 & 3.32 & 0.23 \\
\hline & 0.10 & 3.60 & 3.28 & 0.32 \\
\hline & 0.20 & 3.64 & 3.24 & 0.40 \\
\hline
\end{tabular}

